\title{
EFEITO DE UM PROTETOR FÍSICO NA SEMEADURA DIRETA DE DUAS ESPÉCIES FLORESTAIS EM ÁREA DE DOMÍNIO CILIAR ${ }^{1}$
}

\author{
Ubirajara Contro Malavasi², Jeferson Klein² e Marlene de Matos Malavasi²
}

\begin{abstract}
RESUMO - O ensaio avaliou o uso de uma garrafa plástica tipo PET de $2.000 \mathrm{~mL}$ como protetor físico na semeadura direta de Enterolobium contortisiliquum (Vell.) Morong. e Peltophorum dubium (Spreng.) Taub. em área de domínio ciliar no Oeste do Paraná. Nas semeaduras executadas no outono, inverno e primavera, utilizaram-se quatro sementes pré-embebidas de cada espécie por cova. As avaliações constaram da percentagem acumulada de plântulas vivas por parcela 30 dias após a semeadura (emergência), da percentagem de plântulas vivas 90 dias após a semeadura (sobrevivência) e da percentagem de covas por parcela (formada por 15 covas) com pelo menos uma plântula viva 90 dias após a semeadura (densidade populacional), assim como da altura e diâmetro do colo das plântulas. A semeadura realizada no outono resultou em $45 \%$ de plântulas de timburi vivas 30 dias após a semeadura, enquanto a emergência de plântulas de canafistula (média de 75,5\%) foi indiferente às épocas de semeadura. O uso do protetor aumentou a emergência de plântulas das espécies estudadas quando semeadas no outono (12\%) ou no inverno (10\%), assim como na sobrevivência da semeadura da primavera, e na densidade populacional nas semeaduras de outono e da primavera em covas semeadas com canafístula.
\end{abstract}

Palavras-chave: Revegetação, Crescimento inicial, Enterolobium contortisiliquum e Peltophorum dubium.

\section{THE EFFECTS OF A SHELTER UPON SEEDING OF TWO FOREST TREE SPECIES IN A RIPARIAN AREA}

\begin{abstract}
The study compared the effects of a plastic bottle as a shelter on direct spot seeding of two forest species. Four water soaked seeds of Enterolobium contortisiliquum (Vell.) Morong. (timburi) or Peltophorum dubium (Spreng.) Taub. (canafistula) were spot seeded in autumn, winter or spring in a riparian area located on the western portion of Parana state, Brazil. Calculation of population variables included accumulative percentage of live germinants 30 days after seeding (emergency), percentage of live seedlings 90 days after seeding (survival), percentage of seeded spots per plot (formed by 15 seeding spots) with at least one live seedling (population density), as well as seedling height and diameter. Autumn seeding resulted in $45 \%$ of live timburi germinants 30 days after seeding, while survival of canafistula germinants (average of 75.5\%) was independent of seeding season. The use of shelter on the seeding spot increased emergency of germinants from the two species when seeded in the autumn (12\%) or in the winter (10\%), and increased survival of the spring seeding and population density of autumn or spring seeding seasons with canafistula.
\end{abstract}

Keywords: Revegetatio, Initial growth, Enterolobium contortisiliquum and Peltophorum dubium.

\section{INTRODUÇÃO}

A semeadura direta de espécies florestais revela-se como alternativa econômica para a restauração ecológica em áreas de domínio ciliar, sendo particularmente útil em situações com regeneração natural lenta (WILLISTON e BALMER, 1977), em projetos de recuperação de matas ciliares (FERREIRA et al., 2009) ou como alternativa ao plantio de mudas (WINSA e BERGSTEN, 1994; SUN et al., 1995; DUBOIS et al., 2000; ENGEL e PARROTTA, 2001; CAMARGO et al., 2002; SWEENEY e CZAPKA, 2004).

\footnotetext{
${ }^{1}$ Recebido em 14.10.2008 e aceito para publicação em 02.03.2010.

${ }^{2}$ Universidade Estadual do Oeste do Paraná, UNIOESTE, Brasil. E-mail: <umala@unioeste.br>.
} 
O período crítico para o estabelecimento de mudas de espécies florestais via semeadura direta compreende os primeiros 30 dias (MENEGHELLO e MATTEI, 2004), quando é primordial a proteção inicialmente do diásporo e, em um segundo momento, da plântula contra herbivoria e condições ambientais adversas. Nessa linha, o uso de protetores físicos com a semeadura de espécies florestais objetiva prover um microambiente favorável à germinação e sobrevivência das plântulas (LAHDE, 1974).

No Brasil, Carneiro (1995) recomendou que os protetores fossem atóxicos, transparentes e capazes de reter a umidade do solo. A semeadura direta associada ao uso de protetores físicos proporciona alternativa viável para a revegetação, quando da lentidão da regeneração natural (DÁRIO, 1994). Buscando minimizar as perdas provocadas pelo ataque de pássaros e pelas formigas, assim como a quebra e o carregamento de diásporos e plântulas pela precipitação pluviométrica e pequenos protetores físicos de materiais plásticos com capacidade de 200 a $500 \mathrm{~mL}$ foram testados para proteger os germinantes durante os primeiros meses (MATTEI, 1995, 1998; BRUM et al., 1999; FERREIRA, 2002; FERREIRA et al., 2007).

O banco de sementes em áreas de domínio ciliar em áreas na região Oeste do Paraná exibiu pouca diversidade e reduzido número de sementes viáveis para o re-estabelecimento da vegetação (GASPARINO et al., 2006). Consequentemente, com o objetivo de aumentar o sucesso na revegetação ciliar, o ensaio avaliou o uso de garrafas transparentes tipo PET de $2000 \mathrm{~mL}$ de volume como protetor físico na semeadura direta de duas espécies florestais.

\section{MATERIAL E MÉTODOS}

O ensaio foi implantado em área distante de 5 a 30 m da margem esquerda do riacho Guavirá, Município de Marechal Cândido Rondon, PR, com coordenadas geográficas de 24³4’00" S e 5406’00" $\mathrm{W}$, anteriormente utilizada como pastagem. O solo é classificado como Latossolo Vermelho Eutroférrico (EMBRAPA, 1999), e o clima da região caracteriza-se como subtropical úmido com verões quentes, quando a temperatura atinge valores maiores do que $32{ }^{\circ} \mathrm{C}$ e há tendência de chuvas irregulares naqueles meses. A precipitação média anual atinge 1.500 mm, com umidade média anual de $80 \%$.

Revista Árvore, Viçosa-MG, v.34, n.5, p.781-787, 2010
O ensaio utilizou sementes de Enterolobium contortisiliquum (Vell.) Morong. e Peltophorum dubium (Spreng.) Taub. Recém-colhidas de 10 matrizes do mesmo município da área experimental. As sementes foram secas à sombra e armazenadas em embalagens permeáveis em câmara fria até sua utilização. Sementes danificadas foram descartadas, enquanto as não danificadas foram escarificadas com lixa para madeira $n^{\circ} .80$ e colocadas em béquer com água por 12 horas à temperatura ambiente antes da semeadura. Somente as sementes que mostraram sinais de embebição foram utilizadas no ensaio.

A germinação em laboratório foi quantificada com três repetições de 25 sementes em caixas tipo Gerbox com papel de filtro e temperatura constante de $25{ }^{\circ} \mathrm{C}$, em BOD.

Por conta das irregularidades topográficas e da cobertura de gramíneas na área de ensaio, cada combinação de espécie com presença ou ausência do protetor físico foi representada por 15 covas de semeadura por parcela com espaçamento de 2 x $2 \mathrm{~m}$ e bordadura externa de cada parcela formada com mudas das mesmas espécies. O controle da vegetação herbácea foi executado mensalmente, com coroamento manual ao redor de cada cova.

Medições da temperatura do ar com termômetro THR $-080\left( \pm 0,01^{\circ} \mathrm{C}\right)$ e do fluxo de radiação com quantum radiômetro (LI-250A) realizadas anteriormente à instalação do ensaio indicaram aumento da temperatura do ar e redução no fluxo de radiação na superfície do solo sob o protetor físico, o que descartou a utilização do protetor com a semeadura no verão.

As semeaduras foram realizadas com quatro sementes de cada espécie por cova, a uma profundidade média de 1-2 cm, em 22 de março (outono), 22 de junho (inverno) e 22 de setembro (primavera). Em cada data de instalação do ensaio foram demarcados três blocos, cada um composto por seis parcelas, totalizando 180 covas ou pontos de semeadura em área de $720 \mathrm{~m}^{2}$.

O ensaio foi analisado através de delineamento em blocos casualizados (DBC), em esquema fatorial $3 \times 2 \times 2$ (épocas de semeadura x espécies x protetor de germinação). Como protetor foi usada garrafa plástica tipo PET com volume de $2.000 \mathrm{~mL}$ sem a tampa e com o fundo removido medindo $28 \mathrm{~cm}$ de altura fixada sobre a cova com o auxílio de duas varetas de bambu e fita adesiva. 
As variáveis registradas foram emergência, sobrevivência e densidade populacional. A quantificação da emergência, anotada acumulativamente a cada dois dias até 30 dias após a semeadura, contabilizou a percentagem total de plântulas vivas. A sobrevivência, contabilizada pela percentagem de plântulas vivas, e a densidade populacional, obtida pela percentagem de covas por parcela com pelo menos uma plântula viva, foram contabilizadas 90 dias após a semeadura. Adicionalmente, as variáveis morfométricas altura e diâmetro do colo das plântulas foram anotadas naquela mesma ocasião.

Os valores da emergência, da sobrevivência e da densidade populacional após a transformação em arcosseno $\sqrt{ } \mathrm{x} / 100$, assim como os das variáveis morfométricas, foram submetidos à análise de variância utilizando o programa SISVAR. Na existência de diferença estatística, a comparação das médias foi feita pelo teste de Tukey a 5\% de probabilidade.

\section{RESULTADOS E DISCUSSÃO}

As percentagens de germinação das sementes a serem utilizadas no ensaio resultaram em valores de $67 \%$ para E. contortisiliquum e de $92 \%$ para $P$. dubium, em condições de laboratório. A presença da garrafa plástica transparente utilizada como protetor físico sobre a cova resultou na redução do fluxo de radiação solar e no aumento da temperatura do ar imediatamente acima da superfície do solo (Tabela 1 ).

A presença do protetor de germinação altera o microclima sobre o local da semeadura. Aumento médio da temperatura $\left(+0,8^{\circ} \mathrm{C}\right)$ e da umidade $(+4 \%)$ do ar em garrafas plásticas transparentes utilizadas como protetores de germinação foi reportado por Andrade (2007) no Distrito Federal, e incremento da temperatura do ar $\left(+2,5^{\circ} \mathrm{C}\right)$ em copos plásticos transparentes de $500 \mathrm{~mL}$ foi relatado por Santos Junior et al. (2004) no Sul de Minas Gerais.
A análise dos resultados da emergência revelou interações significativas entre "espécie e época de semeadura" ( $\mathrm{F}=0,12 ; \mathrm{P}<0,01)$, assim como entre "protetor físico e época de semeadura” ( $\mathrm{F}=0,02 ; \mathrm{P}<0,01)$ e entre “espécie e protetor físico” ( $\mathrm{F}=0,01 ; \mathrm{P}<0,05)$.

O desdobramento da interação “espécie e época de semeadura” (Figura 1) mostrou significativa redução na emergência de plântulas de Enterolobium contortisiliquum em função da época de semeadura, o que não foi observado em Peltophorum dubium, espécie cuja percentagem de plântulas foi indiferente às épocas de semeadura.

Os valores decrescentes da emergência de timburi nas condições de campo do ensaio deste estudo podem ser parcialmente justificados pela deterioração das sementes retiradas do local de semeadura e analisadas visualmente. Sementes de timburi quando submetidas ao envelhecimento acelerado, sob condições de alta temperatura e umidade por 84 ou $120 \mathrm{~h}$, resultaram em 0\% de germinação em condições de laboratório (SIRTOLI et al., 2003).

A interpretação da interação “protetor e época de semeadura” (Figura 2) indicou que o uso do protetor físico aumentou a emergência das semeaduras realizadas no outono e no inverno ao elevá-las em 12\% e 10\%, comparadas àquelas sem o uso de protetores, respectivamente. A elevação da temperatura do ar sob a proteção da garrafa plástica (tabela 1 ) nas estações do ano com temperaturas mais frias pode ter contribuído para o aumento na emergência. A influência da temperatura como fator regulador do processo germinativo está bem estabelecido na literatura. O uso de protetores físicos na semeadura direta aumentou a germinação e a sobrevivência na semeadura de espécies tardias como Cedrela fissilis, Copaifera langsdorffii, Enterolobium contortisiliquum, Piptadenia

Tabela 1 - Valores médios da temperatura do ar e do fluxo de radiação com e sem a presença de protetor físico. Table 1 - Mean values of air temperature and radiation flux with and without a seeding shelter.

\begin{tabular}{|c|c|c|c|c|c|c|}
\hline \multirow{4}{*}{$\begin{array}{l}\text { Sensor na } \\
\text { superfície } \\
\text { da cova de } \\
\text { semeadura }\end{array}$} & \multicolumn{6}{|c|}{ Horário das mensurações } \\
\hline & \multicolumn{2}{|c|}{7 horas } & \multicolumn{2}{|c|}{12 horas } & \multicolumn{2}{|c|}{15 horas } \\
\hline & Temperatura & Radiação & Temperatura & Radiação & Temperatura & Radiação \\
\hline & $\left({ }^{\circ} \mathrm{C}\right)$ & $\overline{\left(\mu \mathrm{mol} \mathrm{s} \mathrm{s}^{-1} \mathrm{~m}^{-2}\right)}$ & $\left({ }^{\circ} \mathrm{C}\right)$ & $\left(\mu \mathrm{mol} \mathrm{s} \mathrm{s}^{-1} \mathrm{~m}^{-2}\right)$ & $\left({ }^{\circ} \mathrm{C}\right)$ & $\left(\mu \mathrm{mol} \mathrm{s} \mathrm{s}^{-1} \mathrm{~m}^{-2}\right)$ \\
\hline$\overline{\text { Sem protetor }}$ & $20,75 \quad b$ & 865,0 a & $29,25 \quad b$ & 1653,9 a & $31,12 b$ & 950,2 a \\
\hline Com protetor & 21,19 a & $605,3 \mathrm{~b}$ & 30,80 a & $1260,2 \mathrm{~b}$ & 32,00 a & 795,9 b \\
\hline
\end{tabular}

Médias com a mesma letra na coluna não diferem pelo teste de Tukey a 5\% de probabilidade. 


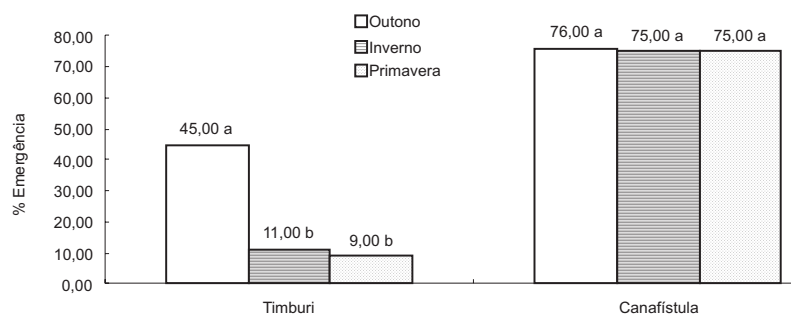

Figura 1 - Emergência de plântulas de Enterolobium contortisiliquum e Peltophorum dubium em função da época de semeadura direta.

Figure 1 - Emergence of Enterolobium contortisiliquum and Peltophorum dubium as a function of season.

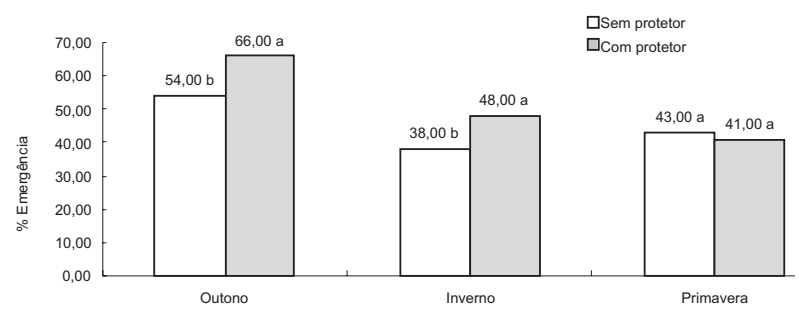

Figura 2 - Emergência com presença ou ausência de protetor após a semeadura direta em função da época de semeadura.

Figure 2 -Emergence with and without a seeding shelter as a function of season.

gonoacantha e Tabebuia serratifolia (SANTOS JÚNIOR et al., 2004), mas não com a emergência e sobrevivência de Senna multijuga, Senna macranthera, Solanum granuloso-leprosum e Trema micrantha (FERREIRA et al., 2007) sob condições do Cerrado brasileiro.

A análise da interação "espécie e protetor" mostrou que enquanto a emergência de plântulas de timburi não foi influenciada pela presença (23\%) ou ausência (20\%) do protetor, a emergência de sementes de canafistula aumentou de $70 \%$ para $81 \%$ com o uso de protetor físico. A reduzida emergência de plântulas de timburi nesse ensaio pode também ser atribuída à presença de fungos, semelhantemente ao constatado por Ferreira et al. (2002) na semeadura direta de Senna multijuga com protetores físicos. Os resultados do ensaio com relação ao efeito do protetor físico foram similares aos obtidos em semeadura direta de timburi e canafístula, em campos abandonados no Rio Grande do Sul (MENEGHELLO e MATTEI, 2004), mas diferem daqueles de Ferreira et al. (2002), na emergência de plântulas de Senna multijuga (Rich.) et Barn, na região Sul de Minas Gerais.
Ensaios realizados em locais com forte sazonalidade climática incentivam o uso de protetores físicos com a semeadura direta. Mattei e Rosenthal (2002), trabalhando com semeadura de Peltophorum dubium no enriquecimento de capoeiras, notaram que o uso de protetor nos pontos semeados aumentou a emergência, em comparação com àqueles pontos não protegidos. Mattei (1997), avaliando o comportamento da emergência de P. taeda sob o efeito de protetores físicos em semeadura direta, observou que os pontos protegidos apresentaram incremento de $62 \%$, comparados com aqueles sem protetores. Esse mesmo autor e colaboradores (2001), avaliando a emergência 30 dias após a semeadura direta de P. elliotti, observaram que os pontos de semeadura protegidos apresentaram aumento de $21 \%$ no número de plântulas emergidas em relação aos pontos não protegidos.

A análise de variância com os resultados da sobrevivência 90 dias após a semeadura constatou a existência de interação estatisticamente significativa entre todas as fontes de variação avaliadas $(\mathrm{F}=12,48$; $\mathrm{P}<0,05$ ). O desdobramento da interação (tabela 2) revelou que a presença do protetor físico aumentou o número total de plântulas vivas de canafistula semeadas na primavera, enquanto não houve efeito sobre as de timburi. Semeaduras no outono e no inverno resultaram em maiores percentagens de plântulas das duas espécies testadas.

As percentagens de plântulas vivas ao final de 90 dias após a semeadura sem protetor, obtidas neste estudo, superam aquelas reportadas por Malavasi et al. (2005) na mesma região e com as mesmas espécies, em face das diferenças no vigor de sementes florestais entre e dentro da espécie e entre épocas de produção, assim como de acordo com o habitat (AGUIAR et al., 1993). Os resultados com a sobrevivência de plântulas de Enterolobium contortisiliquum deste ensaio foram similares aos reportados por Ferreira et al. (2002) que, usando copos plásticos de $250 \mathrm{~mL}$ como protetores físicos nos pontos de semeadura, não constataram diferenças estatísticas em relação à sobrevivência de cinco espécies nativas 90 dias após a semeadura direta, assim como também relatado por Mattei (1995) com plântulas de Cedrela fissilis.

A análise de variância dos valores da densidade populacional (número de pontos de semeadura com pelo menos uma plântula viva 90 dias após a semeadura) apontou a existência de interação entre todos os fatores 
Tabela 2 - Percentagem de plântulas vivas (sobrevivência) de timburi e de canafistula 90 dias após a semeadura direta em função da época de semeadura e do protetor.

Table 2 - Percentage of timburi and canfistula live seedlings (survival) 90 days after direct seeding as a function of season and shelter.

\begin{tabular}{lcr}
\hline & & \\
\hline Época de semeadura & Sem protetor & Com protetor \\
\cline { 2 - 3 } Outono & 58,90 a A & 74,79 a A \\
Inverno & 60,95 a A & C \\
Primavera & 44,45 a B & Canafistula \\
\hline Época de semeadura & & \\
Outono & Sem protetor & Com protetor \\
Inverno & 70,94 a A & 89,48 a A \\
Primavera & 75,02 a A & 98,61 a A \\
\hline
\end{tabular}

Médias seguidas de mesma letra minúscula na linha e maiúscula na coluna não diferem entre si, pelo teste de Tukey a 5\%.

( $F=527,25 ; P<0,01)$. O desdobramento da interação (Tabela 3) permite concluir que com Enterolobium contortisiliquum a presença do protetor aumentou a percentagem de plântulas resultantes da semeadura de inverno, mas não na de primavera. Entretanto, com a densidade populacional de plântulas de Peltophorum dubium, o protetor aumentou a percentagem de plântulas vivas originadas tanto da semeadura de outono quanto da de primavera. O efeito da época de semeadura sobre a densidade populacional indicou que a no outono resultou em maior percentagem de covas com plântulas vivas das duas espécies testadas, indiferentemente da presença do protetor.

Mattei (1995) verificou valores da densidade populacional de Cedrela fissilis e de Pinus taeda em semeadura direta $60 \%$ maiores com a presença de protetor. Além disso, o mesmo autor afirmou que o protetor não permite a movimentação do solo junto às sementes. Na semeadura direta, as maiores perdas acontecem na fase de plântula, quando a herbivoria é fatal para boa parte das plantas (MATTEI e ROSENTHAL, 2002).

A análise das mensurações da altura e do diâmetro do coleto de plântulas 90 dias após a semeadura revelou que plântulas de Enterolobium contortisiliquum atingiram maior altura $(16,28 \mathrm{~cm})$ quando comparadas com as plântulas de Peltophorum dubium $(11,01 \mathrm{~cm})$. Com relação ao efeito da época de semeadura, as maiores alturas ao final de 90 dias foram encontradas em plântulas semeadas no inverno e na primavera, com $15,16 \mathrm{~cm}$ e $17,43 \mathrm{~cm}$, respectivamente, enquanto as semeadas no outono mediram $8,35 \mathrm{~cm}$. A altura atingida pelas plântulas originadas da semeadura no inverno reforça a importância de comparar novas estratégias de revegetação em áreas de domínio ciliar em regiões com sazonalidade climática acentuada.

Tabela 3 - Percentagem de covas com pelo menos uma plântula viva de Enterolobium contortisiliquum e Peltophorum dubium em função do protetor da semeadura.

Table 3 - Percentage of seeding spots with at least one live seedling of Enterolobium contortisiliquum and Peltophorum dubium as a function of season and shelter.

\begin{tabular}{|c|c|c|}
\hline & \multicolumn{2}{|c|}{ Timburi } \\
\hline Época de semeadura & Sem protetor & Com protetor \\
\hline Outono & 65,44 a $\mathrm{A}$ & 77,78 a $\mathrm{A}$ \\
\hline Inverno & 20,00 b B & 37,78 а $\mathrm{B}$ \\
\hline Primavera & 31,11 a $\mathrm{B}$ & 8,89 b C \\
\hline & \multicolumn{2}{|c|}{ Canafistula } \\
\hline Época de semeadura & Sem protetor & Com protetor \\
\hline Outono & 80,00 b A & 100,00 a $\mathrm{A}$ \\
\hline Inverno & 86,67 a $\mathrm{A}$ & 97,78 а $\mathrm{A}$ \\
\hline Primavera & 73,33 b $\mathrm{B}$ & 95,56 а $\mathrm{A}$ \\
\hline
\end{tabular}

Médias seguidas de mesma letra minúscula na linha e maiúscula na coluna não diferem entre si, pelo teste de Tukey a 5\%.

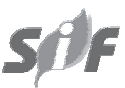

Revista Árvore, Viçosa-MG, v.34, n.5, p.781-787, 2010 
O uso de protetores físicos resultou em altura de $15,96 \mathrm{~cm}$, enquanto em plântulas sem protetor a altura foi de 11,33 cm. Protetores físicos colocados em pontos de semeadura de Senna multijuga (Rich.) Irwin et Barn. e de Senna macranthera (Collad.) Irwin et Barn resultaram em alturas 39\% superiores àquelas originadas de pontos não protegidos (FERREIRA, 2002).

A análise de variância das mensurações do diâmetro do coleto das plântulas ao final de 90 dias detectou diferença estatística entre plântulas das espécies utilizadas com médias de 1,96 e 1,03 mm de plântulas de timburi e de canafistula, respectivamente. Diferentemente da inexistência de efeito do protetor nesse ensaio, Ferreira et al. (2002) constataram incremento de 13\% no diâmetro do coleto em plântulas de Senna multijuga (Rich.) et Barn protegidas, em comparação com o de plântulas nãoprotegidas.

\section{CONCLUSÕES}

Nas condições do ensaio, a emergência de Peltophorum dubium foi maior do que a de Enterolobium contortisiliquum, nas épocas de semeadura avaliadas. O uso de protetores físicos juntamente com a semeadura direta realizada no outono ou no inverno aumentou a percentagem de plântulas vivas 30 dias após a semeadura. A semeadura realizada na primavera resultou na menor sobrevivência e densidade populacional de plântulas das duas espécies 90 dias após a semeadura, enquanto o uso do protetor proporcionou a na obtenção de plântulas com maior altura e diâmetro das duas espécies naquele mesmo período.

A semeadura realizada no outono com ou sem protetor resultou em maior número de covas com pelo menos uma plântula viva tanto de timburi quanto de canafístula. As espécies Enterolobium contortisiliquum e Peltophorum dubium apresentaram potencialidade para a revegetação de matas ciliares através da semeadura direta na região Oeste do Paraná.

\section{REFERÊNCIAS}

AGUIAR, I.B.; PIÑA-RODRIGUES, F.C.M.; FIGLIOLIA, M.B. Sementes Florestais Tropicais. Brasília: ABRATES, 1993. 350 p.
ANDRADE, A.P.A. Avaliação da utilização de protetor físico de germinação e semeadura direta das espécies Copaifera Langsdorffii desf. e Enterolobium Contortisiliquum (Vell.) Morong. em área degradada pela mineração. 2008. 99 f. Dissertação (Mestrado em Engenharia Florestal)Universidade de Brasília, 2008.

BRUM, E. S.; MATTEI, V. L.; MACHADO, A. Emergência e sobrevivência de Pinus taeda L. em semeadura direta a diferentes profundidades. Revista Brasileira de Agrociencias,v. 5, n. 3, p. 190-194, 1999.

CAMARGO, J. L. C.; FERRAZ, I. D. K.; IMAKAWA, A. M. Rehabilitation of degraded areas of central Amazonia using direct sowing of forest tree seeds. Restoration Ecology, v. 10, n. 4, p. 636-644, 2002.

CARneiro, J. G. A. Produção e controle de qualidade de mudas florestais. Curitiba: Universidade Federal do Paraná/FUPEP, UENF, 1995. 451p.

DÁRIO, F. R. A dispersão de sementes pelas aves, Silvicultura, v. 58, p.32-34, 1994.

DUBOIS, M. R.; CHAPPELKA, A. H.; ROBBINS, E.; SOMERS, G.; BAKER, K. Tree shelters and weed control: effects on protection, survival and growth of cherrybark oak seedling planted on a cutover site. New Forests, v. 20, p. 105-118, 2000.

EMPRESA BRASILEIRA DE PESQUISA AGROPECUÁRIA - EMBRAPA. Centro Nacional de Pesquisa de Solos. Sistema Brasileiro de Classificação de Solos. Brasília, 1999. 412p.

ENGEL, V. L.; PARROTTA, J. A. An evaluation of direct seeding for reforestation of degraded lands in central São Paulo state, Brazil. Forest Ecology and Management, v. 152, p. 169-181, 2001.

FERREIRA, R. A. Estudo da semeadura direta visando à implantação de matas ciliares. Lavras, MG 2002. Originalmente apresentada como tese de doutorado, Universidade Federal de Lavras, 2002, 138p. 
FERREIRA, R. A.; DAVIDE, A. C.; BEARZOTI, E.; MOTTA, M. S. Semeadura direta para implantação de matas ciliares: efeito de um protetor físico e do tratamento para superar a dormência de sementes no estabelecimento de Senna multijuga (Rich.) et Barn. In: V SIMPÓSIO NACIONAL DE RECUPERAÇÃO DE ÁREAS DEGRADADAS, 2002, Belo Horizonte. Resumos... Minas Gerais, SOBRADE, 2002. p. 264-265.

FERREIRA, R. A.; DAVIDE, A. C.; BEARZOTI, E.; MOTTA, M. S. Semeadura direta com espécies arbóreas para recuperação de ecossistemas florestais. Cerne, v. 13, n. 3, p. 271-279, 2007.

FERREIRA, R.A. et al. Semeadura direta com espécies florestais na implantação de mata ciliar no Baixo São Francisco em Sergipe. Scientia Forestalis, v.37, n.81, p. 37-46, 2009.

GASPARINO, D. et al. Quantificação do banco de sementes sob diferentes usos do solo em área de domínio ciliar. Revista Árvore, v.30, p.1 - 9, 2006.

LAHDE, E. The effect of seed-spot shelters and cold stratification on pine (Pinus sylvestris L.). Folia Forestalia, n.196, p.1-16, 1974.

MALAVASI, U. C.; GASPARINO, D.; MALAVASI, M.M. Semeadura direta na recomposição vegetal de áreas ciliares: efeitos da sazonalidade, uso do solo, exclusão da predação e profundidade na sobrevivência inicial. Semina: Ciências Agrárias, v.26, p.449 - 454, 2005.

MATTEI, V. L. Preparo de solo e uso de protetor físico, na implantação de Cedrela fissilis V. E Pinus taeda L., por semeadura direta. Revista Brasileira de Agrociência, v. 1. n. 3, p. 127-132, 1995.

MATTEI, V. L. Avaliação de protetores físicos em semeadura direta de Pinus taeda L. Ciência Florestal, v. 7. n.1, p. 91-100, 1997.

MATTEI, V. L. Materiais de cobertura em semeadura de Pinus elliotti Engelm e Pinus taeda L., diretamente no campo. Revista Brasileira de Agrociência, v. 4. n.1, p. 64 - 68, 1998.

MATTEI, V. L. Semeadura direta de Peltophorum dubium (Spreng.) Taub. no enriquecimento de capoeiras. Revista Árvore, v.2, n.1, p. 85-96, 1999.
MATTEI, V. L.; ROSENTHAL, M. D. Semeadura direta de canafístula (Peltrophorum dubium (Spreng.) taub.) no enriquecimento de capoeiras. Revista Árvore, v. 26 , n. 6, p. 649-654, 2002.

MATTEI, V. L.; ROMANO, C. M.; TEIXEIRA, M. C. C. Protetores físicos para semeadura direta de Pinus elliotti Engelm. Ciência Rural, v.31, n. 5, p. 775-780, 2001.

MENEGHELLO, G. E.; MATTEI, V. L. Semeadura direta de timbaúva (Enterolobium contortisiliquum), canafístula (Peltophorum dubium) e cedro (Cedrela fissilis) em campos abandonados. Ciência Florestal, v.14, n. 2, p. 21-27, 2004.

SANTOS JÚNIOR, N.A.; BOTELHO, S.A.; DAVIDE, A.C. Estudo da germinação e sobrevivência de espécies arbóreas em sistema de semeadura direta, visando à recomposição de mata ciliar. Cerne, v.10, n.1, p. 103-117, 2004.

SIRTOLI et al. Comportamento de sementes de timburi (Enterolobium contortisiliquum Vell.) submetidas ao envelhecimento precoce. In: CONGRESSO BRASILEIRO DE SEMENTES, 13., 2003, Gramado. Informativo ABRATES.., Gramado, 2003, p. 380.

SWEENEY, B. W.; CZAPKA, S. J. Riparian forest restoration: why each site needs an ecological prescription. Forest Ecology and Management, v. 192, p. 361 - 373, 2004.

SUN, D.; DICKINSON, G. R.; BRAGG, A. L. Direct seeding of Alphitonia petriei (Rhamnaceae) for gully revegetation in tropical northern Australia. Forest Ecology and Management, v. 73, p. 249-257, 1995.

WILLISTON, H. L.; BALMER, W. E. Direct seeding of southern pines - a revegetation alternative. Forest Management Bull, Atlanta, Ga. Forest Service, USDA, 6p, 1977.

WINSA, H.; BERGSTEN, U. Direct seeding of Pinus sylvestris using microsite preparation and invigorated seed lots of different quality: 2-year results. Canadian Journal of Forest Research, v. 24, p. 77-86, 1994.

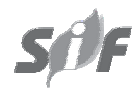

Revista Árvore, Viçosa-MG, v.34, n.5, p.781-787, 2010 